\title{
Sensitivity of Meloidogyne incognita second- stage juvenile hatch, motility and viability to pure cucurbitacins and cucurbitacin-containing phytonematicides
}

\section{Zakheleni P Dube, Phatu W Mashela \& Dirk de Waele}

To cite this article: Zakheleni P Dube, Phatu W Mashela \& Dirk de Waele (2018): Sensitivity of Meloidogyne incognita second-stage juvenile hatch, motility and viability to pure cucurbitacins and cucurbitacin-containing phytonematicides, South African Journal of Plant and Soil, DOI: 10.1080/02571862.2018.1464220

To link to this article: https://doi.org/10.1080/02571862.2018.1464220

曲 Published online: 11 Jun 2018.

Submit your article to this journal $\widetilde{ }$

Џ Article views: 4

Q View related articles $\longleftarrow$

View Crossmark data $\asymp$ 


\title{
Sensitivity of Meloidogyne incognita second-stage juvenile hatch, motility and viability to pure cucurbitacins and cucurbitacin-containing phytonematicides
}

\author{
Zakheleni P Dube ${ }^{1 *}$, Phatu W Mashela ${ }^{1}$ and Dirk de Waele ${ }^{1,2}$ \\ ${ }^{1}$ Green Biotechnologies Research Centre, University of Limpopo, Sovenga, South Africa \\ 2 Laboratory of Tropical Crop Improvement, Department of Biosystems, Faculty of Bioscience Engineering, University of \\ Leuven (KU Leuven), Heverlee, Belgium; and Unit for Environmental Sciences and Management, North-West University, \\ Potchefstroom, South Africa \\ *Corresponding author, email: zakheleni_dube@yahoo.com
}

\begin{abstract}
Previous claims suggested that pure active ingredients from botanicals were less effective in pest management than their fermented crude-extracts. The objective of this study was to compare the toxicity of pure (98\%) cucurbitacin $A$ and $B$ on nematode bioactivities with those of their fermented crude-extracts, the Nemarioc-AL and

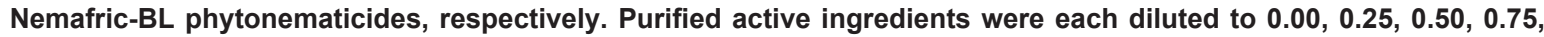
$1.00,1.25,1.50,1.75,2.00,2.25$ and $2.50 \mathrm{mg} \mathrm{ml}^{-1}$ and their fermented crude-extracts to $0.0 \%, 0.5 \%, 1.0 \%, 1.5 \%, 2.0 \%$, $2.5 \%, 3.0 \%, 3.5 \%, 4.0 \%, 4.5 \%$ and $5.0 \%$ phytonematicide. The exposure time for second-stage juveniles (J2) hatch, motility and viability of the $\mathrm{J} 2$ to each concentration was 24,48 and $72 \mathrm{~h}$. The overall sensitivities $(\Sigma k)$ of $\mathrm{J} 2 \mathrm{hatch}$ to Nemarioc-AL, cucurbitacin A, Nemafric-BL and cucurbitacin B were 1, 30, 5 and 2 units, respectively, for motility 7, 12, 2 and 12 units, respectively, and for viability 2, 4, 1 and 4 units, respectively. Generally, nematodes displayed high sensitivities to cucurbitacin-containing phytonematicides than to their respective purified active ingredients (cucurbitacins). In conclusion, the cucurbitacin-containing phytonematicides were more effective in nematode suppression than their purified active ingredients.
\end{abstract}

Keywords: botanicals, CARD, Cucumis species, $k$-value, plant extracts, triterpenoids

Introduction

During the past decade, efforts to develop botanicals as biopesticides have increased (Okwute 2012). As a result, a number of promising biopesticides have been identified (Manju and Sankari Meena 2015). Nonetheless, many issues remain to be solved before these biopesticides can be effectively applied. One of these issues is the claim that the purified active ingredients from botanicals are less effective compared with the fermented crudeextracted biopesticides (Javed et al. 2008; Okwute 2012; Chaudhary et al. 2013). For instance, the Aza formulation, which contains azadirachtin, a purified ingredient from neem seed, showed no effect on the motility and viability, and a lower effect on second-stage juveniles (J2) hatch of root-knot nematode (Meloidogyne species) compared with crude neem cake and leaf extracts (Javed et al. 2008). Grandison (1992 cited by Javed et al. 2008) also did not observe any direct effects of purified substances from neem seed kernels, such as aza, salanine and nimbin, on J2 of Meloidogyne javanica.

The first step in determining the bioactivity of plant extracts in most studies consists of in vitro bioassays of purified substances. The inactivity of some of the purified substances resulted in potential phytonematicides failing to move beyond in vitro bioassays, limiting progress in the development of phytonematicides. Okwute (2012) suggested two causes for the observed inactivity of purified substances: (1) less desirable solvents used during purification and
(2) the bioactivity of crude extracts is based on synergism among some of their ingredients.

The Curve-fitting Allelochemical Response Data (CARD) computer-based model was developed to assess responses of organisms toward increasing concentration of allelochemicals (Liu et al. 2003). Responses of plant-parasitic nematodes to increasing concentration of phytonematicides have been characterised by densitydependent growth patterns, which were quantified by quadratic curves and seven biological indices (Liu et al. 2003). The sensitivity index $(k)$ has been described as the number of $\ln (D+1)$ transformations, where $k$-values serve as biological indicators of the degree of sensitivity of test organisms to increasing concentration of allelochemicals. The $k$ index has been used to measure the degree of toxicity of phytonematicides to crops (Mafeo and Mashela 2010; Mafeo et al. 2011; Pelinganga et al. 2013; Mashela et al. 2015). Usually, $k$-values start from zero and increase as discrete numbers when the sensitivity of the test organism to the allelochemical decreased (Liu et al. 2003). Thus, the sensitivity of the test organism to the allelochemical is inversely proportional to the $k$-value. The overall sensitivity $(\Sigma k)$ is the sum of all the $k$-values associated with a specific test organism and, in the case of plants, it is the sum of all $k$-values of the tested organs (Mashela et al. 2015).

The sensitivity of Meloidogyne incognita to cucurbitacincontaining phytonematicides and how this sensitivity 
compares with that to the purified active ingredients of these phytonematicides using the CARD-generated sensitivity index has not been examined. The objective of this study was to compare the bioactivity of cucurbitacin A and cucurbitacin B on $\mathrm{J} 2$ hatch, motility and viability of M. incognita J2 with the bioactivity of the crude-extracted phytonematicides Nemarioc-AL and Nemafric-BL, respectively, of which these cucurbitacins are one of the ingredients.

\section{Materials and methods}

\section{Preparation of the pure extracts and crude-extracted phytonematicides}

Purified (ca. 98\% purity) cucurbitacin A and B were obtained from ChemFaces (Wuhan, China). Approximately $1000 \mu \mathrm{g}$ of each cucurbitacin was dissolved in $5 \mu \mathrm{L}$ methanol to enhance solubility prior to adding $1 \mathrm{~mL}$ distilled water to make a stock solution. In two separate trials of cucurbitacins, different concentrations of cucurbitacin A and $B$ made from diluting the stock solution with distilled water $(0.00,0.25,0.50,0.75,1.00,1.25,1.50,1.75,2.00,2.25$ and $2.50 \mu \mathrm{g}$ cucurbitacin $\mathrm{mL}^{-1}$ distilled water) were each pipetted into a 9-cm-diameter petri dish. Nemarioc-AL and Nemafric-BL were prepared by Effective Microorganisms ${ }^{\mathrm{TM}}$ $\left(E M^{\mathrm{TM}}\right)$ fermentation of oven-dried ground fruits from Cucumis myriocarpus and C. africanus, respectively (Pelinganga et al. 2012). The two Cucumis species were propagated as described by Shadung (2016). Of each phytonematicide, 10 concentrations $(0.50 \%, 1.00 \%, 1.50 \%$, $2.00 \%, 2.50 \%, 3.00 \%, 3.50 \%, 4.00 \%, 4.50 \%$ and $5.00 \%$ ) were made in distilled water. Distilled water and $0.005 \%$ methanol were included as controls in the bioassay with the pure extracts, while distilled water and EM ${ }^{\mathrm{TM}}$ (Microzone, Pretoria, South Africa) were included as controls in the bioassay with the crude-extracted phytonematicides.

\section{Collection of Meloidogyne incognita eggs and second- stage juveniles (J2)}

Dark-brown coloured egg masses of $M$. incognita were obtained from infected two-month-old tomato (Solanum lycopersicum L. 'Floradade') plants grown in soil in pots in a greenhouse. Egg masses were dislodged from the roots using a toothpick, placed in $1 \% \mathrm{NaOCl}$ solution and shaken for $30 \mathrm{~s}$ to surface-sterilise the egg masses and remove the gelatin matrix, before thorough rinsing in distilled water. Surface-sterilised eggs were used for the J2 hatch bioassay. Freshly-hatched J2 were obtained by transferring surface-sterilised eggs in Petri dishes containing $10 \mathrm{~mL}$ distilled water and placed in an incubator at $25 \pm 2{ }^{\circ} \mathrm{C}$. J2 that hatched during the first $24 \mathrm{~h}$ were discarded. J2 that hatched during the subsequent $48 \mathrm{~h}$ were used in the bio-assay (Dube and Mashela 2016).

\section{Effect on $\mathrm{J} 2$ hatch}

The study was conducted at the Green Biotechnologies Research Centre, University of Limpopo, South Africa $\left(23^{\circ} 53^{\prime} 10^{\prime \prime} \mathrm{S}, 2^{\circ} 44^{\prime} 15^{\prime \prime} \mathrm{E}\right)$ under in vitro conditions. The effect of the different concentrations of the pure extracts and the crude-extracted phytonematicides on the J2 hatch of the J2 was separately tested in 9-cm-diameter petri dishes. An average of 107 freshly collected eggs were transferred to each petri dish containing $10 \mathrm{~mL}$ concentration. The petri dishes were placed in a completely randomised design with three replications in an incubator at $25 \pm 2{ }^{\circ} \mathrm{C}$. The number of $\mathrm{J} 2$ that had hatched after 24 , 48 and $72 \mathrm{~h}$ were counted using a stereomicroscope. The bioassay was repeated three times.

\section{Effect on motility and viability of second-stage juveniles (J2)}

The effect of the different concentrations of the pure extracts and crude-extracted phytonematicides on the motility and viability of $\mathrm{J} 2$ was examined following a modification of the method described by Wuyts et al. (2006). The assessments were carried out using 9-cm-diameter petri dishes containing $10 \mathrm{~mL}$ of each concentration. Approximately 450 freshly-hatched $\mathrm{J} 2$ were added to each concentration. The petri dishes were placed in a completely randomised design with three replications in an incubator at $25 \pm 2{ }^{\circ} \mathrm{C}$. After 24 , 48 and $72 \mathrm{~h}$, each petri dish was emptied into a counting chamber and the number of immobile $\mathrm{J} 2$ counted using a stereomicroscope. The J2 were considered immobile when no movement was observed during $2 \mathrm{~s}$ even after prodding with a needle. Concentrations were considered motileinhibitive when significantly more $\mathrm{J} 2$ became immobilised compared with the controls (Wuyts et al. 2006). The immobile $\mathrm{J} 2$ were stained in $0.015 \%$ methylene blue for $1 \mathrm{~h}$. All dark blue-stained J2 were considered dead (Saifullah 2002). The bioassay was repeated three times.

\section{Statistical analysis}

Number of hatched, immobile and dead J2 were $\log _{10}(x+1)$ transformed to homogenise variances (Gomez and Gomez 1984) prior to analysis of variance using SAS 9.2 software (SAS Institute 2008). Significant treatment means for variables were further subjected to CARD modelling to generate sensitivity values (Mashela et al. 2015).

\section{Results and discussion}

The overall sensitivities $(\Sigma k)$ of $\mathrm{J} 2$ hatch to Nemarioc-AL, cucurbitacin A, Nemafric-BL and cucurbitacin B were 1, 30, 5 and 2 units, respectively (Table 1). In contrast, those for $\mathrm{J} 2$ motility were 7, 12, 2 and 12 units, respectively (Table 2), and for $\mathrm{J} 2$ viability were 2, 4, 1 and 4 units, respectively (Table 3 ). The bioactivity of the pure cucurbitacins and the fermented crude extract phytonematicides on $\mathrm{J} 2$ hatch, motility and viability of $M$. incognita J2 observed supports the results of other studies (Ibrahim et al. 2006; Lazzeri et al. 2004; Wuyts et al. 2006). Ibrahim et al. (2006) and Lazzeri et al. (2004) reported the nematostatic and nematicidal activity of pure chemical substances derived from plant extracts, whereas Javed et al. (2007) observed the same activities from crude extracts of other plants. Nevertheless, differences in sensitivities between the cucurbitacin-containing crude extracts and the pure cucurbitacins were observed.

The highest difference observed was the sensitivity of eggs to J2 hatch inhibition caused by Nemarioc-AL and cucurbitacin A, with Nemarioc-AL having a higher inhibitive effect compared with its active ingredient cucurbitacin A. In general, in terms of $\mathrm{J} 2$ hatch, motility and viability the eggs and $\mathrm{J} 2$ of $M$. incognita were more sensitive to the crude extracts than to their purified active 
Table 1: Sensitivity of Meloidogyne incognita second-stage juvenile (J2) hatch to Nemarioc-AL phytonematicide, cucurbitacin A, Nemafric-BL phytonematicide and cucurbitacin B after 24, 48 and 72 h exposure

\begin{tabular}{|c|c|c|c|c|c|c|c|c|c|c|c|c|}
\hline \multirow{2}{*}{ Biological index } & \multicolumn{3}{|c|}{ Nemarioc-AL } & \multicolumn{3}{|c|}{ Cucurbitacin A } & \multicolumn{3}{|c|}{ Nemafric-BL } & \multicolumn{3}{|c|}{ Cucurbitacin B } \\
\hline & 24 & 48 & 72 & 24 & 48 & 72 & 24 & 48 & 72 & 24 & 48 & 72 \\
\hline Threshold stimulation $\left(D_{\mathrm{m}}\right)$ & 13.87 & 0.01 & 0.08 & 0.61 & 0.52 & 0.16 & 4.05 & 0.19 & 4.89 & 1.38 & 1.37 & 0.73 \\
\hline Saturation point $\left(R_{\mathrm{h}}\right)$ & 12.70 & 0.02 & 0.16 & 0.41 & 0.64 & 1.12 & 0.70 & 0.09 & 0.37 & 1.06 & 0.68 & 0.26 \\
\hline $0 \%$ inhibition $\left(D_{0}\right)$ & 13.29 & 0.04 & 0.25 & 0.82 & 1.28 & 2.24 & 3.08 & 0.60 & 3.00 & 2.28 & 1.71 & 0.76 \\
\hline $50 \%$ inhibition $\left(D_{50}\right)$ & 15.17 & 4.12 & 6.89 & 1.05 & 1.75 & 3.31 & 3.84 & 2.71 & 6.47 & 3.34 & 2.39 & 1.49 \\
\hline $100 \%$ inhibition $\left(D_{100}\right)$ & 20.77 & 9.92 & 23.09 & 1.12 & 1.92 & 4.28 & 4.94 & 10.90 & 12.37 & 4.40 & 3.07 & 3.02 \\
\hline$R^{2}$ & 0.96 & 0.96 & 0.95 & 0.86 & 0.86 & 0.81 & 0.97 & 0.96 & 0.98 & 0.90 & 0.88 & 0.95 \\
\hline Sensitivity index $(k)$ & 0 & 0 & 1 & 5 & 5 & 20 & 1 & 4 & 0 & 0 & 0 & 2 \\
\hline Overall sensitivity $(\Sigma k)$ & & 1 & & & 30 & & & 5 & & & 2 & \\
\hline
\end{tabular}

Table 2: Sensitivity of Meloidogyne incognita second-stage juvenile (J2) motility inhibition to Nemarioc-AL phytonematicide, cucurbitacin A, Nemafric-BL phytonematicide and cucurbitacin B after 24,48 and $72 \mathrm{~h}$ exposure

\begin{tabular}{|c|c|c|c|c|c|c|c|c|c|c|c|c|}
\hline \multirow{2}{*}{ Biological index } & \multicolumn{3}{|c|}{ Nemarioc-AL } & \multicolumn{3}{|c|}{ Cucurbitacin A } & \multicolumn{3}{|c|}{ Nemafric-BL } & \multicolumn{3}{|c|}{ Cucurbitacin B } \\
\hline & 24 & 48 & 72 & 24 & 48 & 72 & 24 & 48 & 72 & 24 & 48 & 72 \\
\hline Threshold stimulation $\left(D_{\mathrm{m}}\right)$ & 34.13 & 29.35 & 0.37 & 5.76 & 22.41 & 9.29 & 5.91 & 0.13 & 5.05 & 4.32 & 9.64 & 13.57 \\
\hline Saturation point $\left(R_{\mathrm{h}}\right)$ & 291.67 & 587.00 & 22462.14 & 1.64 & 1.68 & 1.71 & 285.84 & 4.13 & 263.53 & 1.70 & 0.30 & 1.68 \\
\hline $0 \%$ inhibition $\left(D_{0}\right)$ & 454.57 & 880.50 & 22462.51 & 5.34 & 13.73 & 7.21 & 297.66 & 6.26 & 273.63 & 4.71 & 5.27 & 9.31 \\
\hline $50 \%$ inhibition $\left(D_{50}\right)$ & 617.47 & 1174.00 & 22462.88 & 9.04 & 25.77 & 12.71 & 309.46 & 10.29 & 283.69 & 7.72 & 10.24 & 16.93 \\
\hline $100 \%$ inhibition $\left(D_{100}\right)$ & 780.37 & 1467.50 & 22463.28 & 12.74 & 37.82 & 18.21 & 321.26 & 14.22 & 293.69 & 10.73 & 15.21 & 24.56 \\
\hline$R^{2}$ & 0.97 & 0.97 & 0.97 & 0.99 & 0.99 & 0.99 & 0.96 & 0.96 & 0.98 & 0.99 & 0.99 & 0.99 \\
\hline Sensitivity index $(k)$ & 1 & 2 & 4 & 4 & 4 & 4 & 0 & 2 & 0 & 3 & 5 & 4 \\
\hline Overall sensitivity $(\Sigma k)$ & & 7 & & & 12 & & & 2 & & & 12 & \\
\hline
\end{tabular}

Table 3: Sensitivity of Meloidogyne incognita second-stage juvenile (J2) viability inhibition to pure cucurbitacin A, Nemarioc-AL phytonematicide, cucurbitacin $\mathrm{B}$ and Nemafric-BL phytonematicide. $R^{2}=$ coefficient of determination

\begin{tabular}{lcccc}
\hline Biological index & Nemarioc-AL & Cucurbitacin A & Nemafric-BL & Cucurbitacin B \\
\hline Threshold stimulation $\left(D_{\mathrm{m}}\right)$ & 6.77 & 20.70 & 1.33 & 13.66 \\
Saturation point $\left(R_{\mathrm{h}}\right)$ & 1.56 & 1.69 & 1.53 & 1.67 \\
$0 \%$ inhibition $\left(D_{0}\right)$ & 5.73 & 12.89 & 27.43 & 9.34 \\
$50 \%$ inhibition $\left(D_{50}\right)$ & 9.89 & 24.08 & 34.19 & 17.00 \\
$100 \%$ inhibition $\left(D_{100}\right)$ & 14.06 & 35.28 & 41.53 & 24.67 \\
$R^{2}$ & 0.99 & 0.99 & 0.99 & 0.99 \\
\hline Overall sensitivity $(\Sigma k)$ & 2 & 4 & 1 & 4 \\
\hline
\end{tabular}

ingredients. A similar trend was reported in several other studies (Javed et al. 2008; Okwute 2012). Okwute (2012) suggested two possible explanations to the different responses to plant crude extracts. The first explanation could be the undesirable solvents used during purification. For instance, the hexane extracts of neem (Azadirachta indica) seed were ineffective in causing losses of viability in Heterodera glycines J2 compared with water extracts, which were 240 times more effective (Silva et al. 2008). Alcohol extracts of Chrysanthemum coronarium, Pistacia palestina, Matricaria discoidea and Tagetes patula (Ibrahim et al. 2006), Xanthium strumarium and Lantana camara (Chaudhary et al. 2013) did not have any significant effect on $M$. incognita J2 hatch even though their aquous extracts were widely reported to be bioactive (Singh and Prasad 2014).

The second explanation could be that there are many active substances in plant crude extracts and that these may work in synergy to induce bioactivities on nematodes. Although the presence of multiple active substances in plant crude extracts is relatively well documented (Ibrahim et al. 2006; Nzanza and Mashela 2012), there is limited information on their synergistic interactions. Such synergistic effects were observed in NICOSAN, a drug used in the treatment of sickle cell anemia, when it was found to be less potent to sickle cells and more toxic to healthy cells when individual components were separately tested (Okwute 2012). Aza, a purified neem seed extract, affected motility and viability of $M$. javanica J2 less compared with neem cake and leaf crude extracts (Javed et al. 2008). Grandison (1992 cited by Javed et al. 2008) also reported the inactivity of salinine, Aza and nimbin, pure extracts of neem seed kernels, against the viability of $\mathrm{J} 2$ of $M$. javanica. These reports could explain the observed low sensitivities of $M$. incognita to pure active ingredients compared with their fermented crude extracts in the current study.

In this study, $M$. incognita response ranged from moderate to highly tolerant to the bioactivity of cucurbitacin A ( $k=4-30$ units), and similar trends were observed in cucurbitacin $B$ ( $k=2-12$ units) tests. The difference in $k$-values between cucurbitacin $A$ and $B$ could be explained in terms of the polarity of cucurbitacin $A$, which readily breaks down to cucumin $\left(\mathrm{C}_{27} \mathrm{H}_{40} \mathrm{O}_{9}\right)$ and leptodermin $\left(\mathrm{C}_{27} \mathrm{H}_{38} \mathrm{O}_{8}\right)$. After $48 \mathrm{~h}$, cucurbitacin $\mathrm{A}$ was still very bioactive as indicated by the 
relatively higher sensitivities of the $\mathrm{J} 2$, but after $72 \mathrm{~h}$ the $\mathrm{J} 2$ became moderately sensitive, this being more evident in $\mathrm{J} 2$ hatch (Table 1). This was most probable due to accumulation of cucumin and leptodermin, which could also suggest that $\mathrm{J} 2$ hatch is less sensitive to these two substances compared with the parent compound, cucurbitacin A. Evidence of bioactivities of cucumin and leptodermin was reported in certain insects (Damalas 2011). In contrast, due to the stability of cucurbitacin $B, M$. incognita sensitivity remained high to this substance (Table 1 ).

Melodogyne incognita J2 hatch was highly sensitive to the two phytonematicides as shown by low $k$-values across all incubation periods, with a higher sensitivity to Nemarioc-AL compared with Nemafric-BL. Pelinganga (2013) observed similar trends with tomato plant variables being highly sensitive $(\Sigma k=0)$ to these two products, but with more plant organs having higher sensitivities to Nemarioc-AL compared with Nemafric-BL. Seed germination of various plants also had high sensitivities to crude extracts of $C$. myriocarpus fruit in granular formulation (Mafeo et al. 2011). The superior performance of traditionally produced crude-extracted phytonematicides over their purified ingredients reported in this study and in other studies does not conform to the registration requirements where purified materials are preferred.

\section{Conclusion}

The sensitivity index is used as an indicator of nematode sensitivity to cucurbitacin-containing phytonematicides and their purified active ingredients demonstrate that the latter were more than the former. Consequently, the products should be used in crude extract form. Given that crude plant extract preparation is easy to make, their high effectiveness makes them an ideal tool for the management of plantparasitic nematodes in resource-poor farming communities.

\section{References}

Chaudhary KK, Haile A, Ayresea ZG, Semereab G, Weldegergish T. 2013. Nematicidal activity of Eritrean weed plants against the root-knot nematode Meloidogyne incognita. Nematropica 43: 207-215.

Damalas CA. 2011. Potential uses of turmeric (Curcuma longa) products as alternative means of pest management in crop production. Plant Omics Journal 4: 136-141.

Dube ZP, Mashela PW. 2016. Nemafric-BL phytonematicide induces egg hatch inhibition in Meloidogyne incognita. Acta Agriculturae Scandinavica, Section B-Soil and Plant Science: 66: 384-386.

Gomez KA, Gomez AA. 1984. Statistical procedures for agricultural research (2nd edn). New York: John Wiley.

Ibrahim SK, Traboulsi AF, El-Haj S. 2006. Effect of essential oils and plant extracts on hatching, migration and mortality of Meloidogyne incognita. Phytopathologia Mediterranea 45: 238-246.

Javed N, Gowen SR, El-Hassan SA, Inam-ul-Haq M, Shahina F, Pembroke B. 2008. Efficacy of neem (Azadirachta indica) formulations on biology of root-knot nematodes (Meloidogyne javanica) on tomato. Crop Protection 27: 36-43.

Javed N, Gowen SR, Inam-Ul-Haq M, Abdullah K, Shahina F. 2007. Systemic and persistent effect of neem (Azadirachta indica) formulations against root-knot nematodes, Meloidogyne javanica and their storage life. Crop Protection 26: 911-916.

Lazzeri L, Curto G, Leoni O, Dallavalle E. 2004. Effects of glucosinolates and their enzymatic hydrolysis products via myrosinase on the root-knot nematode Meloidogyne incognita (Kofoid and White) Chitw. Journal of Agricultural and Food Chemistry 52: 6703-6707.

Liu DL, An M, Johnson IR, Lovett JV. 2003. Mathematical modeling of allellopathy. III. A model for curve-fitting allellochemical dose responses. Nonlinearity in Biology, Toxicology, and Medicine 1: 37-50.

Mafeo TP, Mashela PW. 2010. Allelopathic inhibition of seedling emergence in dicotyledonous crops by Cucumis bio-nematicide. African Journal of Biotechnology 9: 8349-8354.

Mafeo TP, Mashela PW, Mphosi MS. 2011. Sensitivity of selected Alliaceae seedlings to crude extract of Cucumis myriocarpus fruits. African Journal of Agricultural Research 6: 158-164.

Manju P, Sankari Meena K. 2015. Antinemic properties of the botanicals. International Journal of Science and Nature 6: 125-134.

Mashela PW, Dube ZP, Pofu KM. 2015. Managing the phytotoxicity and inconsistent nematode suppression in soil amended with phytonematicides. In: Meghvansi MK, Vorma A (eds), Organic amendments and soil suppressiveness in plant disease management. Soil Biology 46. Cham: Springer International Publishing. pp 147-173.

Nzanza B, Mashela PW. 2012. Control of whiteflies and aphids in tomato by fermented plant extracts of neem leaf and wild garlic. African Journal of Biotechnology 11: 16077-16082.

Okwute SK. 2012. Plants as potential sources of pesticidal agents: a review. In: Soundararajan RP (ed.), Pesticides: advances in chemical and botanical pesticides in technology. Rijeka: Intech. pp 207-232.

Pelinganga OM. 2013. Developing bio-nematicides using indigenous Cucumis africanus and Cucumis myriocarpus fruits for tomato production system. PhD thesis, University of Limpopo, Sovenga, South Africa.

Pelinganga OM, Mashela PW, Mphosi MS, Mafeo TP, Dube ZP. 2013. Using density-dependent growth patterns of tomato plants to establish application intervals for $3 \%$ Nemarioc-A phytonematicide. African Crop Science Conference Proceedings 11: 343-347.

Pelinganga OM, Mashela PW, Nzanza B, Mphosi MS. 2012. Baseline information on using fermented crude extracts from Cucumis africanus fruit for suppression of Meloidogyne incognita and improving growth of tomato plant. African Journal of Biotechnology 11: 11407-11413.

Saifullah A. 2002. New blue R: the best stain for finding out the life status of nematode eggs. Pakistan Journal of Plant Sciences 2: 63.

SAS Institute 2008. SAS ${ }^{\circledR} 9.2$ qualification tools user's guide. Cary, NC: SAS Institute.

Shadung KG. 2016. Quality protocols for Nemarioc-AL and Nemafric-BL phytonematicides and their respective chemical residues in tomato fruits. PhD thesis, University of Limpopo, Sovenga, South Africa.

Silva JCT, Oliveira RDL, Jham GN, Aguiar NDC. 2008. Effect of neem seed extracts on the development of the soybean cysts nematode. Tropical Plant Pathology 33: 171-179.

Singh AU, Prasad D. 2014. Management of plant-parasitic nematodes by the use of botanicals. Journal of Plant Physiology and Pathology 2: 1-10.

Wuyts N, Swennen R, De Waele D. 2006. Effects of plant phenylpropanoid pathway products and selected terpenoids and alkaloids on the behavior of the plant-parasitic nematodes Radopholus similis, Pratylenchus penetrans and Meloidogyne incognita. Nematology 8: 89-101. 